\title{
Experimental Study of Water Hammer Pressure in a Commercial Pipe
}

\author{
Ashish Kumar Patel ${ }^{1}$ \\ '(School of Mechanical Engineering, Lovely Professional University, India)
}

\begin{abstract}
Water hammer is a phenomenon caused by change in flow velocity and valve closing/opening time. It is undesirable. It causes because pressure transient in the pipe, vibration and noise. Excessive pressure causes pipe fracture by rupture. A review of literature has shown that earlier researchers concentrated more on the analysis of water hammer by method of characteristic while comparative study of method of water hammer analysis is insufficient. In the present study experimental and analytical analysis of water hammer pressure in a commercial pipe has been studied and analyzed. Method of characteristic (MOC), arithmetic method, theoretical method and experimental method are used in this thesis. In MOC, an element-wise definition is used for all the devices that may be used in a pipeline system and the corresponding equations are derived in an element-wise manner. The proper equations defining the behavior of each device including pipes are derived and assembled to form the final system of equations to be solved for the unknown nodal heads. Used method allows for any arbitrary combination of devices in the pipeline system. MOC was concluded it is superior to other methods.
\end{abstract}

Keywords: flow control valve, pipeline system and valve closing time/valve opening time.

\subsection{WATER HAMMER}

\section{INTRODUCTION}

Transient flow is the transition from one steady state to another steady state in a fluid flow system. Transient flow occurs in all fluids, confined and unconfined. A transition is caused by a disturbance to the flow. In a confined system, such as a water pipeline, an abrupt change to the flow that causes large pressure fluctuations is called water hammer. The name comes from the hammering sound the sometimes occurs during the phenomenon.

The water hammer phenomenon is an important consideration in design in many hydraulic structures due to extreme variations in pressure it causes. For example, the dramatic pressure rise can cause pipes to rupture. Accompanying the high pressure wave, there is a negative wave, which is often overlooked, can cause very low pressures leading to the possibility of contaminant intrusion. Water hammer is a common but serious problem in residential plumbing systems. It puts potentially damaging extra stress and strain on pipes, joints, and fixtures. The noise associated with water hammer can be a nuisance as well.

\subsection{EFFECT OF WATER HAMMER ON THE PIPE}

Rapid pressure changes are a result of rapid changes in flow, which generally occur in a pipe system after pump shut-off, although it may also occur at pump start or at valve opening or closing. Because of the compressibility of water and the elasticity of pipes, pressure waves will then propagate in the pipe until they are attenuated at a velocity, which is dependent upon pipe material and wall thickness.

The effects of the water hammer vary, ranging from slight changes in pressure and velocity to sufficiently high pressure or vacuum through to failure of fittings, and burst pipes. Figure 1 shows burst castiron pipe due to water hammer pressure. This pipe thickness and pipe material is not sufficient to sustain the water hammer pressure. Therefore pipe burst.

J. Izquierdo and Iglesias, (2001) developed a suitable mathematical modeling of the different ingredient in hydraulic system is necessary to get, useful results, which help fulfill these objectives. In this paper mathematical modeling used to develop computer program to simulate the hydraulic transient in simple pipe. The calculations are typically very time-consuming and depending on characteristics of the system very complicated and difficult to organize. 


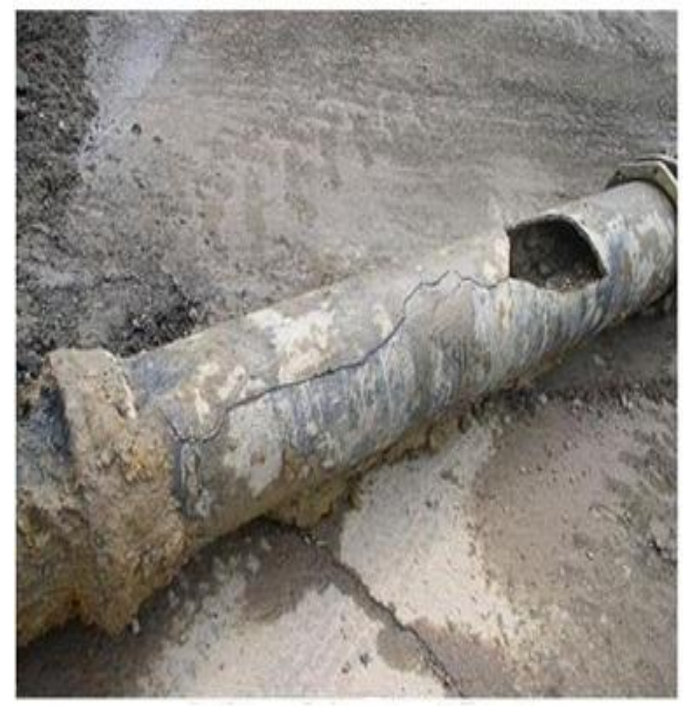

Fig. 1: Cast iron pipe broken from water hammer

J. Izquierdo and Iglesias, (2003) developed the mathematical model described is generalized to complex pressurized hydraulic systems. To model the behavior of the fluid within the ducts, use is made of the so-called elastic model, which is numerically solved by the methods of characteristics. The main objective of this paper hinges on the treatment of the boundary conditions that allow developing a general model virtually representing every combination of elements at a given location of the system.

Bergant and Simpson, (2006) observed that water hammer with column separation from the discovery of the phenomenon in the late $19^{\text {th }}$ century, the recognition of its danger in the 1930s, the development of numerical methods in the 1960s and 1970s, to the standard models used in commercial software packages in the late 20th century. A comprehensive survey of laboratory tests and field measurements is given. The review focuses on transient vaporous cavitation. Gaseous cavitation and steam condensation are beyond the scope of the paper.

\section{EXPERIMENTAL METHODOLOGY}

\section{1 EXPERIMENTAL SETUP}

The general layout of experimental setup is shown in figure 2. The setup consists of reservoir, pipe line, valve, discharge tank, water level indicator and u-tube mercury manometers.

A constant head $9 \mathrm{~m}$ at reservoir of volume $3.5 \times 3.5 \times 3.5 \mathrm{~m}^{3}$ is available from datum line. Water flows from the reservoir to the valve through the connecting pipe line of diameter $5 \mathrm{~cm}$. The measuring tank is been installed for measurements of velocity at different closing/opening of valve conditions. A u-tube manometer (height of $2 \mathrm{~m}$ ) is been installed at the upstream of the valve at different pipe locations. Right limb of manometer is connected to pipe and another limb of manometer is opened to atmosphere.

\subsection{EXPERIMENTAL PROCEDURE}

- First find out manometer height (both left and right limb) when valve was fully opened, and calculated pressure inside the pipe. And also measured velocity by direct discharge method.

- Note down the manometer height (both left and right limb) for the $25 \%$ closure and calculated pressure inside the pipe line. Then Water hammer pressure is been calculated from the measured values. And also measured velocity by direct discharge method at $25 \%$ of valve closing.

- Same procedure is been followed for the $50 \%, 75 \%$, and $100 \%$ valve closing and got water hammer pressure at different valve closing conditions.

- Same procedure is been followed for the $0 \%, 25 \%, 50 \%, 75 \%$, and $100 \%$ valve opening and got water hammer pressure at different valve opening conditions 


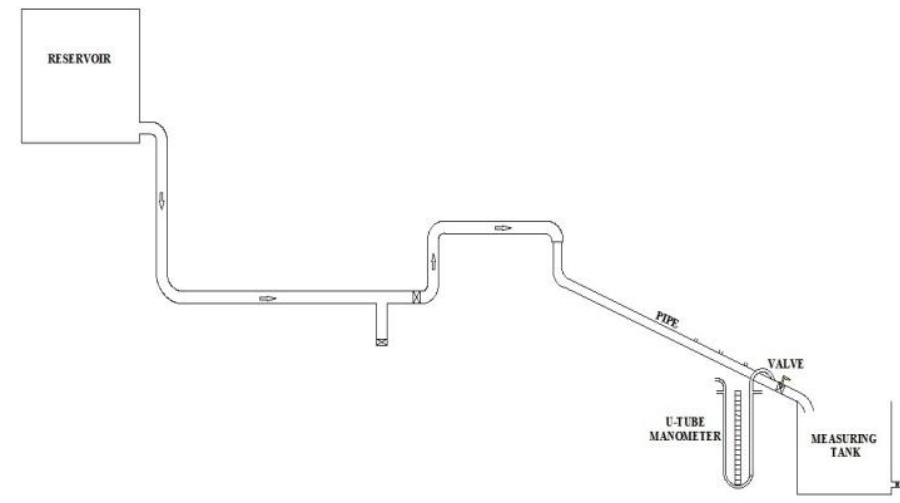

Fig. 2: Experimental setup

\section{RESULTS}

The present chapter presents the graphical representation of experimental data and analytical data. All the water hammer pressure analysis considered in the present work has been computed from measured data and are plotted against different percentage of valve closing/opening.

\subsection{VARIATION OF WATER HAMMER PRESSURE ALONG THE PIPELINE}

Figure 3 shows the variation of water hammer pressure along the pipeline measured by manometer at upstream of the valve at different percentage of valve closing. This fig shows water hammer pressure remains constant along the pipeline. It is because time taken by the water hammer wave for reaching the reservoir and coming back to valve $2 \mathrm{~L} / \mathrm{a}=0.027 \mathrm{sec}$. is too small and manometer reading cannot be taken in such a small time. Concluded that manometer is not accurate device for the study of water hammer pressure.

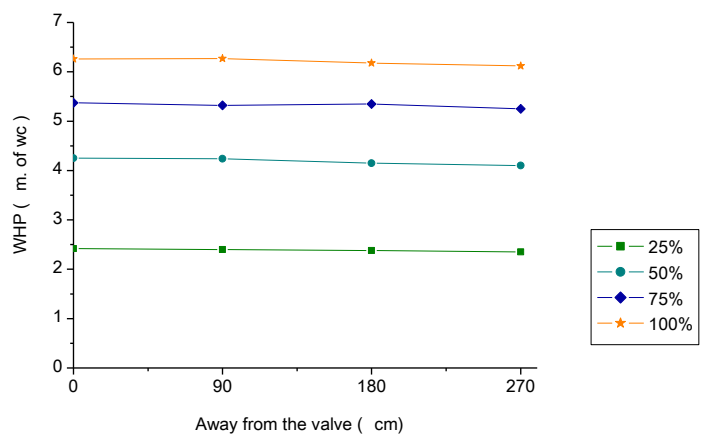

Fig. 3: Variation of water hammer pressure along the pipeline

\subsection{VARIATION OF WATER HAMMER PRESSURE ALONG THE PERCENTAGE OF VALVE CLOSING}

Figure 4 shows the variation of water hammer pressure along the percentage of valve closing. Here valve closing time is $0.3 \mathrm{sec}, 0.5 \mathrm{sec}, 0.6 \mathrm{sec}$, and $0.7 \mathrm{sec}$ for $25 \%, 50 \%, 75 \%$, and $100 \%$ of valve closing respectively. Various methods to find out water hammer pressure have been compared. In this Fig. graph represents arithmetic WHP, method of characteristic WHP, theoretical WHP, and experimental WHP. This Fig. shows good agreement of the arithmetic method, method of characteristic (MOC) and theoretical method to each other at $25 \%, 50 \%, 75 \%$, and $100 \%$ of valve closing. However experimental results agree reasonably well from the theoretical and analytical analysis. This is expected that mercury manometer is not accurate device for water hammer studies. In case of different percentage of valve closing positive water hammer pressure generated. 


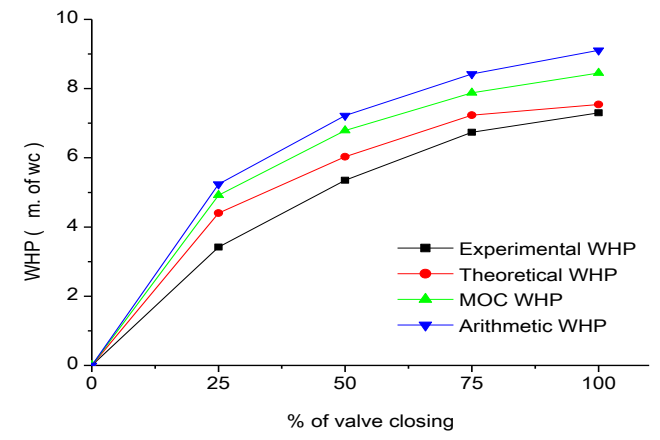

Fig. 4: Variation of water hammer pressure along the percentage of valve closing

\subsection{VARIATION OF WATER HAMMER PRESSURE ALONG THE PERCENTAGE OF VALVE CLOSING FOR THE ANOTHER SET OF VALVE CLOSING TIME}

Figure 5 shows the variation of water hammer pressure along the percentage of valve closing. Here experiments carried out for another set of valve closing time. Valve closing time is $0.9 \mathrm{sec}, 1.6 \mathrm{sec}, 2.1 \mathrm{sec}$, and $2.5 \mathrm{sec}$ for $25 \%, 50 \%, 75 \%$, and $100 \%$ of valve closing respectively. In this fig. graph represents arithmetic WHP, experimental WHP, method of characteristic WHP, and theoretical WHP. This figure shows good agreement of the experimental method, method of characteristic and theoretical method to each other at $25 \%$, $50 \%, 75 \%$, and $100 \%$ of valve closing. It has been concluded that arithmetic method does not show the good agreement with results obtained from the other methods. It implies that the arithmetic method is not suitable for very slow valve closer.

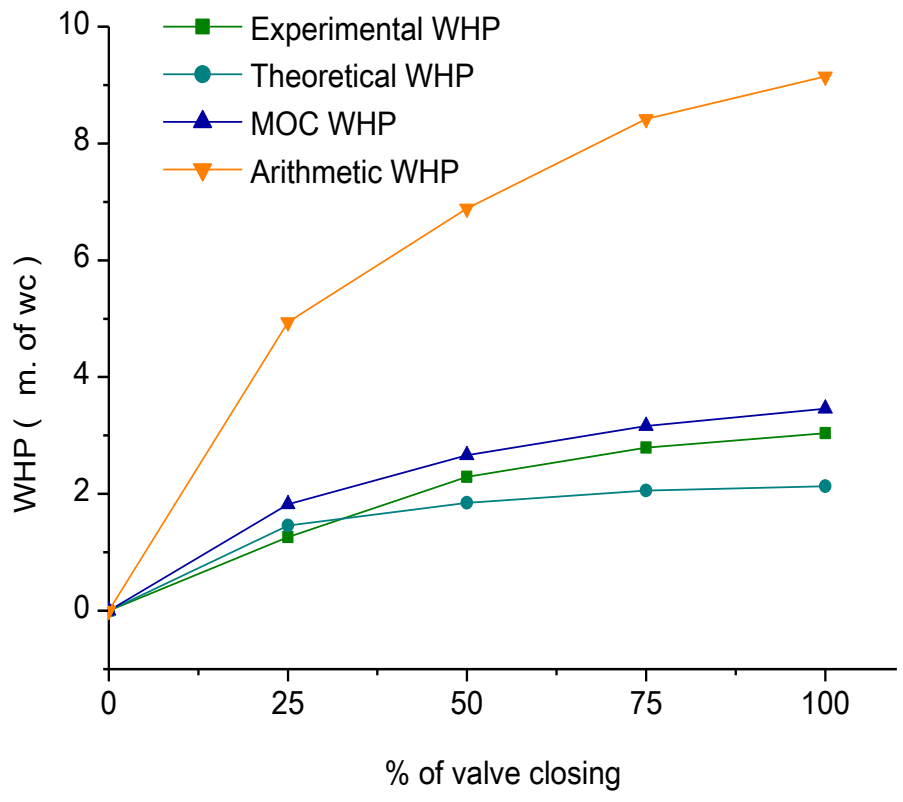

Fig. 5: Variation of water hammer pressure along the percentage of valve closing

\subsection{VARIATION OF WATER HAMMER PRESSURE ALONG THE PERCENTAGE OF VALVE OPENING}

Figure 6 shows the variation of water hammer pressure along the percentage of valve opening. Experiments were carried out to find out water hammer pressure for the different valve opening. Here valve 
opening time is $0.3 \mathrm{sec}, 0.5 \mathrm{sec}, 0.6 \mathrm{sec}$, and $0.7 \mathrm{sec}$ for $25 \%, 50 \%, 75 \%$, and $100 \%$ of valve opening respectively. In this fig. graph represents arithmetic WHP, experimental WHP, method of characteristic WHP, and theoretical WHP.

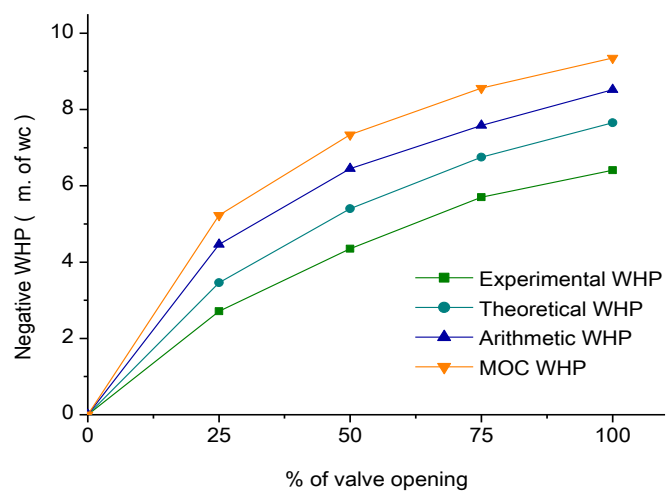

Fig. 6: Variation of water hammer pressure along the percentage of valve opening

Graph shows the reasonable agreement of method of characteristic, arithmetic method and theoretical method. However experimental results agree reasonably well with the theoretical and analytical analysis. In case of different percentage of valve opening negative water hammer pressure generated.

\subsection{VARIATION OF WATER HAMMER PRESSURE ALONG THE PERCENTAGE OF VALVE OPENING FOR THE ANOTHER SET OF VALVE OPENING TIME}

Figure 7 shows the variation of water hammer pressure along the percentage of valve opening. Here experiments carried out for another set of valve opening time. Valve opening time is $0.9 \mathrm{sec}, 1.6 \mathrm{sec}, 2.1 \mathrm{sec}$, and $2.5 \mathrm{sec}$ for $25 \%, 50 \%, 75 \%$, and $100 \%$ of valve opening respectively. In this fig. graph represents arithmetic WHP, method of characteristic WHP, experimental WHP, and theoretical WHP. This fig. shows good agreement of the experimental method, method of characteristic and theoretical method to each other at $25 \%$, $50 \%, 75 \%$, and $100 \%$ of valve opening. It has been concluded that arithmetic method does not show the good agreement with results obtained from the other methods. It implies that the arithmetic method is not suitable for very slow valve opening.

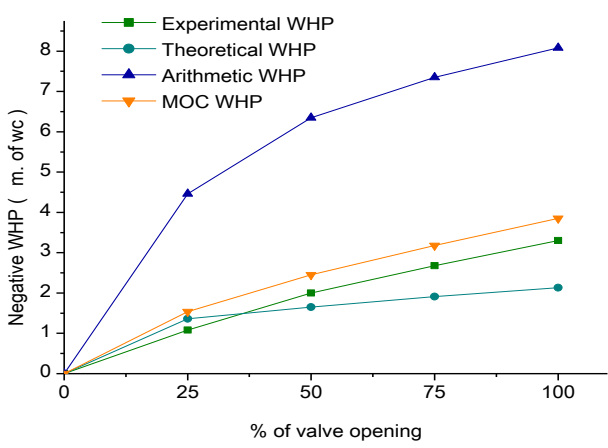

Fig. 7: Variation of water hammer pressure along the percentage of valve opening

\section{CONCLUSION}

Experiments for analysis of water hammer pressure in a commercial pipe were conducted and analytical and theoretical methods were used for different percentage of valve closing and opening. The following conclusions are drawn from the studies. 
1. Water hammer pressure increases in a commercial pipe with percentage increase of valve closing/opening.

2. Water hammer pressure depends upon the valve closing/opening time. It was observed that WHP is more when valve closing/opening time is less.

3. Water hammer pressure is maximum when flow control valve is fully and suddenly closed.

4. From the present investigation, it is found that arithmetic method gives good agreement with the actual results only when the time taken to close or open the valve is $T_{C} \leq 0.7 \mathrm{sec}$. However arithmetic method is not suitable for very slow valve closer $\left(T_{C}>0.7 \mathrm{sec}\right)$.

5. It was found that method of characteristic gives good agreement with theoretical values for any valve closing/opening time.

\section{REFERENCES}

[1] Afshar M. H., and M. Rohani, "Water hammer simulation by implicit method of characteristic", Department of Civil Engineering, Iran

[2] University of Science and Technology, Narmak, Tehran, Iran, 2008

[3] Batterton Shawn, "Water Hammer: An Analysis of Plumbing Systems, Intrusion, and Pump Operation", Thesis on Master of Science In

[4] Civil Engineering of Virginia Polytechnic Institute, Blacksburg Virginia, 2006.

[5] Bergant A., A. R. Simpson, and A.S. Tijsseling, "Water Hammer With Column Separation”, Journal of Fluids and Structures $22,135-$

[6] 171,2006

[7] Dudlik, A., Scho nfeld S.B.H., Hagemann, O., and Fahlenkamp H, "'Water hammer and cavitational hammer in process plant pipe

[8] systems", Kerntechnik 68 (3), 91-96, 2003.

[9] Ferrante M., and Brunone B., 'Pipe System Diagnosis and Leak Detection by Unsteady-State Tests-1: Harmonic Analysis', Adv.

[10] Water Resour. 26, pp. 95-105, 2002.

[11] Ghidaoui M. S., and Kolyshki, A. A., “Stability Analysis of Velocity Profiles in Water-Hammer Flows', J. Hydraul. Eng. 127 6!, pp.

[12] 499-512, 2001.

[13] Ghidaoui M.S., Zhao M., McInnis D.A., and Axworthy D.H., “A review of water hammer theory and practice”, ASME Appl Mech Rev

[14] 2005;58(1):49-76, 2005.

[15] Izquierdo J., and P.L. Iglesias, "Mathematical Modeling of Hydraulic Transient in Simple Systems”, Fluid Mechanics Group,

[16] Polytechnic University of Valencia, Spain, 2001.

[17] Izquierdo, J. and P.L. Iglesias, "Mathematical Modeling of Hydraulic Transient in Complex Systems", Fluid Mechanics Group,

[18] Polytechnic University of Valencia, Spain, 2003.

[19] Liou, J. and Parks, D. “Water Hammer Induced by a Line Break. Pipelines”, pp. 1602-1611. doi 10.1061/9780784413692.145, 2014. 